\title{
Effects of an Intensive Inpatient Rehabilitation Program in Elderly Patients with Obesity
}

\author{
Simona Budui ${ }^{a}$ Francesco Bigolin $^{b}$ Francesca Giordano ${ }^{a}$ \\ Stefania Leoni $^{a} \quad$ Michela Berteotti $^{a}$ Erica Sartori ${ }^{a} \quad$ Laura Franceschini $^{a}$ \\ Micol Taddei ${ }^{a}$ Sabrina Salvetti ${ }^{a} \quad$ Fulvio Castiglioni ${ }^{a} \quad$ Federica Gillic \\ Spyros Skafidas $^{c}$ Federico Schena $^{c}$ M. Letizia Petroni ${ }^{a} \quad$ Luca Busetto $^{b}$ \\ a "Centro per la Cura dell'Obesità," Casa di Cura "Solatrix," Rovereto, Italy; b Dipartimento \\ di Medicina, Università degli Studi di Padova, Padua, Italy; ${ }^{~}$ CeRiSM, Centro Ricerca Sport \\ Montagna e Salute, Università di Verona, Rovereto, Italy
}

\section{Keywords}

Ageing · Obesity · Nutrition · Physical activity · Multidimensional management ·

Rehabilitation

\section{Abstract}

Objective: The aim of this study was to assess the short-term effectiveness of an intensive inpatient multidimensional rehabilitation program (MRP), including diet, exercise, and behavioral therapy, in elderly patients with severe obesity. Methods: Forty-four elderly patients (old; age $69.3 \pm 3.5$ years, BMI $41.9 \pm 14.9$ ) were analyzed against 215 younger patients (young; age $48.2 \pm 18.5$ years, BMI $43.9 \pm 9.4$ ), who were used as controls. All patients underwent MRP, based on group therapy guided by a multidisciplinary team (physicians, dietitians, exercise trainers, psychologists). We evaluated changes in anthropometry, cardiovascular risk factors, physical fitness, quality of life, and eating behavior. Results: After 3 weeks of MRP, we observed a reduction in body weight (old $-3.8 \%$, young $-4.3 \%$ ), BMI (old $-3.9 \%$, young $-4.4 \%$ ), waist circumference (old $-3.4 \%$, young $-4.1 \%$ ), total cholesterol (old $-14.0 \%$, young $-15.0 \%$ ), and fasting glucose (old $-8.3 \%$, young $-8.1 \%$ ), as well as improved performance in the SixMinute-Walk Test (old $+28.7 \%$, young $+15.3 \%$ ), chair-stand test (old $+24.8 \%$, young $+26.9 \%$ ), and arm-curl test (old $+15.2 \%$, young $+27.3 \%$ ). Significant improvement was registered in all other analyzed domains. Conclusion: Our 3-week MRP provided significant clinical and functional improvement, which was similar between elderly and younger patients with severe obesity. In the long-term, this may be translated into better quality of life, through better management of obesity-associated morbidities and reduced frailty. 
Budui et al.: Inpatient Rehabilitation in Elderly Patients with Obesity

\section{Introduction}

The prevalence of obesity has dramatically increased worldwide over the past decades, and this led the World Health Organization to declare a global obesity epidemic, considering the negative impact that obesity has on public health [1]. Furthermore, obesity is associated with greater risk of developing several chronic diseases including cardiovascular disease, diabetes mellitus, cancer, and osteoarthritis [2] with consequent increased risk of disability $[3,4]$.

At the same time, a steady increase in life expectancy has been reported, with projection indicating that the European population over 65 years will reach $30 \%$ by 2060 [5]. As individuals live longer, chronic health concerns greatly affect their quality of life. Likewise, the prevalence of obesity in the older population is on the rise, thus becoming one of the greatest public health concerns in the elderly, as it is associated with increased cardiometabolic risk, physical disability, impaired quality of life and sexual dysfunctions, lower urinary tract symptoms, as well as decreased cognitive function and dementia [6, 7].

In addition, obesity in the elderly is associated with decreased ability to perform physical activity, which determines a higher risk for frailty. A report of the English Longitudinal Study of Ageing has shown that frailty in community-dwelling men and women ( $>65$ years old) was related to Body Mass Index (BMI) in a U-shape manner; extremely low or high BMI are associated with increased frailty [8]. Furthermore, obesity is associated with accelerated biological ageing process, as indicated by increased shortening of telomere length [9]. Another important aspect associated with ageing is change in body composition, with progressive loss of lean mass (especially muscle mass) and strength, a condition defined as sarcopenic obesity [10]. Hence, adipose accumulation and muscle loss are cyclically reinforcing, so that frailty can be markedly progressive, determining a direct impact on self-care and increased health costs.

Although several studies demonstrate the negative impact of obesity in the elderly, the recommendations for obesity management in this population are still scarce. Nevertheless, lifestyle modification through healthy diet and regular physical activity is considered the standard of care and the first step in obesity management $[11,12]$, while other therapeutic interventions (pharmacotherapy and bariatric surgery) have been demonstrated to be beneficial. Albeit the number of elderly subjects in these trials is limited, it becomes clear that the primary goal in this population is the reduction of adiposity and preservation of muscle mass and function, in order to prevent frailty [13]. In this direction, nutritional education and physical exercise represent the cornerstone, and can be implemented through programs of personalized or group-based behavioral therapy [11, 12].

The aim of our study was to assess the short-term effects on health and functional capacity of an intense inpatient rehabilitation program, including behavior intervention, diet, regular exercise and lifestyle counselling, in a group of elderly patients with severe obesity as compared to younger ones.

\section{Methods}

Patients

A total of 259 adult patients with severe obesity and obesity-related comorbidities consecutively admitted to a multidimensional rehabilitation program (MRP) from 1st January 2016 to 1st April 2017 were included in the present study. Patients with a major orthopedic, neurologic, or psychiatric disease, as well as those with a clinical indication to use a very low-calorie diet (i.e., prior to bariatric, orthopedic or cardiac surgery) were excluded by the study. According to their age, subjects were divided into two groups, young ( $<65$ years old, $n=215$ ) and old ( $\geq 65$ years old, $n=44$ ). During MRP, patients were followed by a multidisciplinary team and underwent group as well as individualized interventions. 
Budui et al.: Inpatient Rehabilitation in Elderly Patients with Obesity

\section{Description of the Rehabilitation Program}

The MRP has been developed and conducted at the "Solatrix" Clinic, Rovereto, Trentino region, Italy, and it has been previously described [14]. Briefly, the admission was consented in accordance with the criteria of appropriateness for inpatient obesity rehabilitation released by the Italian Society for Obesity [15] and the costs were covered by the Italian National Health Service. The MRP was conducted in groups of 12-14 patients. At the beginning and at the end of the MRP, all patients underwent a multidimensional assessment regarding clinical status, cardiovascular risk, eating behavior, quality of life, and physical performance.

\section{Medical Evaluation}

At the beginning of the MRP, patients underwent a complete clinical evaluation including medical history, physical examination and assessment of cardiovascular risk factors, in order to identify obesityrelated comorbidities and adjust accordingly medical therapy, as previously described [14]. Serum levels of glucose (Glc), glycated hemoglobin (HbA1c), total cholesterol (TC), HDL-cholesterol (HDL), triglycerides (TG), and uric acid were assessed at admission and discharge. Patients were diagnosed with type 2 diabetes if they had fasting Glc $\geq 126 \mathrm{mg} / \mathrm{dL}$ or $\mathrm{HbA} 1 \mathrm{c} \geq 6.5 \%$ or if they were under antidiabetic therapy [16]. Hypertension was defined as blood pressure $\geq 140 / 90 \mathrm{~mm} \mathrm{Hg}$ or the use of any antihypertensive drug [17]. Nonalcoholic fatty liver disease was diagnosed by abdominal ultrasound [18]. Obstructive sleep apnea syndrome was diagnosed according to the results of a nocturnal instrumental registration of the breathing pattern during sleep and standardized diagnostic criteria [19]. Osteoarthritis (OA) was defined clinically as the presence of chronic pain in the weight-bearing joints with or without the use of pain-suppressing medications. If necessary, a psychiatric evaluation was made.

\section{Nutritional Assessment and Intervention}

Once a week, patients underwent anthropometric evaluation. Body weight (BW) was measured to the nearest $0.1 \mathrm{~kg}$ using a regularly calibrated electronic calibrate balance, in light clothes and without shoes. Body height was measured to the nearest $0.5 \mathrm{~cm}$ with the subject standing erect and barefooted using a stadiometer with a movable piece levelled with skull vault. BMI was calculated as weight in kilograms divided by height in meters squared. Waist circumference (WC) was measured to the nearest $0.5 \mathrm{~cm}$ on a horizontal plane at the midpoint between the lowest rib and the iliac crest, usually corresponding to the level of the umbilicus, at the end of a normal expiration, with the subject standing erect with relaxed abdominal muscles, arms at the side, and feet together [20]. Neck circumference was measured to the nearest $0.5 \mathrm{~cm}$ at the mid-neck level, between mid-cervical spine and mid-anterior neck, just below the cricoid cartilage [21]. In addition, patients underwent bioelectric impedance analysis (BIA; BIA 101 Anniversary device, Akern). Indexes of body composition, fat-free mass $(\mathrm{kg} / \mathrm{m})$, fat mass $(\mathrm{kg} / \mathrm{m})$, total body water $(\mathrm{TBW}, \mathrm{L} / \mathrm{m})$, were calculated by taking into consideration BIA and anthropometric measurements (BW, body height, sex, and age).

After a baseline nutritional assessment including a 24-h dietary recall and diet history, each patient received a personalized diet plan, prescribed by the dietitian. Diet was designed to elicit a caloric deficit of $800-1,000 \mathrm{kcal} /$ day with respect to the estimated individual daily total energy requirements, calculated according to basal metabolic rate (BMR) estimated with the Harris-Benedict equation, and adjusted for physical activity [22]. Total protein intake was set to $0.8-1 \mathrm{~g} / \mathrm{kg}$ of ideal BW (calculated as the BW corresponding to a BMI of 22.5-25.0) and approximately $20 \%$ of the daily energy intake, with carbohydrates representing $50-55 \%$ and fat $25-30 \%$ of daily intake [23]. In addition, daily educational meetings were organized in order to provide proper information and skills to enhance lifestyle modification and restore correct eating habits.

\section{Psychological Evaluation and Support}

All patients admitted to the obesity rehabilitation program attended once-a-week individual session with an experienced psychologist and two weekly group meetings conducted by the same psychologist (the first one concerning mind-set and emotions involved on patient's eating behaviors; the second one being a motivational group). Psychological approach was based on the cognitive-behavioral therapy of obesity [24] as well as a systemic/strategic approach [25]. Psychological individual sessions initially aimed at a diagnostic assessment and to the listing of weight-related problems [26]. The subsequent aim was to increase patient's awareness concerning emotional eating and their own mind-set (automatic thoughts) concerning eating behaviors [27]. A particular focus was placed on relapse prevention and weight regain. Instruments 
used during psychological individual interviews included food/emotional diary, weight problem formulation, problem solving, mindful eating [28], and other cognitive behavioral techniques. The motivational group focused on the trans-theoretical model and the wheel of change of Prochaska and Di Clemente [29], while the other group focused on increasing patient's awareness about the relation between food and emotions, and on learning cognitive and behavioral ways to identify and to manage internal and external critical situations. A psychologist leads the meeting by using assertive abilities of patients in order to make them recognize their own food-related needs, experiences and desires, and making them aware of their own emotionality.

Health-related quality of life was analyzed with the standard (4-week) recall version 2.0 of the 36-item Health Survey (SF-36) questionnaire form. The SF-36 measures the following eight subscales: physical functioning, social functioning, role limitations due to a physical problem, role limitations due to an emotional problem, mental health, vitality, bodily pain, and general health perception. The eight subscales form two distinct higher-ordered summary scales: the Physical Component Summary Scale (PCS) and the Mental Summary Component Scale (MCS) [30]. Binge eating was tested with the use of the Binge Eating Scale (BES) [31].

Functional Evaluation and Exercise Prescription

A graded cardiopulmonary exercise test (CPET) was performed for the aerobic assessment of patients. CPET was conducted on an electromagnetically braked cycle ergometer (Bike RHC 400; CLE Elettromedicali, San Bellino, Italy). After $1 \mathrm{~min}$ of rest at the standing position and $1 \mathrm{~min}$ of freewheel at a constant cadence between 55 and $65 \mathrm{rpm}$, the workload was set at 30 (females or deconditioned males) or $60 \mathrm{~W}$ (males) and was increased by $15 \mathrm{~W}$ every 2 min until volitional exhaustion. Patients were continuously monitored with a 12-lead electrocardiogram (XScribe5; Mortara Instrument Inc., Milwaukee, WI, USA) and a pulse oximeter (PalmSAT 2500; Nonin Medical Inc., Plymouth, MN, USA), while oxygen consumption $\left(\mathrm{VO}_{2}\right)$, carbon dioxide production $\left(\mathrm{VCO}_{2}\right)$, and pulmonary ventilation (VE), were measured breath-by-breath through an opencircuit gas analysis system (K5; Cosmed srl, Rome, Italy). Careful calibration of flow sensors and gas analysis system was performed before each test according to manufacturer's instructions. Cardiorespiratory parameters $\left(\mathrm{VO}_{2}, \mathrm{VCO}_{2}, \mathrm{VE}, \mathrm{HR}\right)$ and power output (PO) were determined at peak exercise, as well as at the first ventilatory threshold $\left(\mathrm{VT}_{1}\right)$. Peak values were determined from the average of the last $20 \mathrm{~s}$ of the incremental test, while $\mathrm{VT}_{1}$ was determined by visual inspection using the following detection criteria: (a) the workload level at which the VE starts to exponentially increase (VT 1 -VE); (b) the workload corresponding to the first increase in the ventilatory equivalent of $\mathrm{O}_{2}$ produced in the absence of a concomitant increase in $\mathrm{VE} \cdot \mathrm{VCO}_{2}{ }^{-1}$ $\left(\mathrm{VT}_{1}-\mathrm{VE} \cdot \mathrm{VO}_{2}{ }^{-1}\right)$; (c) the workload corresponding to the first increase produced in the end-tidal partial pressure of oxygen $\left(\mathrm{VT}_{1}-\mathrm{PetO}_{2}\right)[32,33]$.

Functional capacity was also assessed through the Six-Minute Walk Test (6MWT), as well as Chair Stand Test (CST) and Arm Curl Test (ACT). 6MWT was performed according the standard protocol recommended by the American Thoracic Society [34]. Briefly, the 6MWT test was conducted in a 30-m hallway marked every $5 \mathrm{~m}$ with tapes on the floor. Subjects were instructed to walk from end to end covering the longest possible distance for $6 \mathrm{~min}$. When time elapsed, the distance covered was determined and recorded in meters. During CST, starting from a seated position, subjects were asked to complete as many full stands as possible in $30 \mathrm{~s}$ on a chair without arms with a seat height of $43 \mathrm{~cm}$. During ACT, subjects were seated on a chair and asked to perform as many curls as possible through a full range of motion, using a hand weight ( $5 \mathrm{lbs}$ for women and $8 \mathrm{lbs}$ for men) within $30 \mathrm{~s}$. For both CST and ACT, score was the total number of stands or curls respectively, executed correctly within the 30-s time limit $[35,36]$.

After the initial evaluations, patients were divided in two exercise groups, based on their level of physical fitness and comorbidities. Each group then performed $2 \mathrm{~h}$ of exercise per day, $1 \mathrm{~h}$ in the morning and $1 \mathrm{~h}$ in the afternoon. All sessions included 5-10 min of warm-up, 30-40 min of main work, and 5-10 min of cooldown and 5-10 min of stretching. For aerobic exercise, cycle ergometer or treadmill was the main modality, and intensity was set around $\mathrm{VT}_{1}$, with individual adjustments according to perception of effort or other symptoms (e.g., joint pain). Exercises for muscle strength and resistance were performed with dumbbells, ankle and wrist weights, elastic bands, or the subject's own weight as a resistance. During each session, a total of 10-15 sets of 12-25 repetitions targeting the major muscle groups of the upper and lower body and the trunk were performed. As for aerobic exercise, intensity and volume were individualized. All functional tests (CPET, 6MWT, CST, ACT) were performed at admission, and repeated before discharge, to evaluate progress and adjust individual exercise indications, as patients were encouraged to continue regular exercise as part of an active lifestyle after the end of the MRP. 
Budui et al.: Inpatient Rehabilitation in Elderly Patients with Obesity

Table 1. Baseline characteristics registered at the beginning of the rehabilitation programme in 259 patients consecutively admitted between January 1st, 2016, and April 1st, 2017 (young <65 years old vs. old $>65$ years old)

\begin{tabular}{lccc}
\hline & Young & Old & $p$ value \\
\hline Total & $215(83)$ & $44(17)$ & \\
Age, years & $48.2 \pm 11.5$ & $69.3 \pm 3.5$ & $<0.001$ \\
Male & $70(32.6)$ & $16(36.4)$ & $\mathrm{ns}$ \\
Female & $145(67.4)$ & $28(63.6)$ & $\mathrm{ns}$ \\
Body weight, kg & $121.4 \pm 29.2$ & $112 \pm 21.6$ & 0.043 \\
BMI & $43.9 \pm 5.1$ & $43.9 \pm 4.2$ & $\mathrm{~ns}$ \\
Waist circumference, cm & $130.4 \pm 18.6$ & $129.3 \pm 14.9$ & $\mathrm{~ns}$ \\
Neck circumference, cm & $43.9 \pm 5.1$ & $43.9 \pm 4.2$ & $\mathrm{~ns}$ \\
\hline Type 2 diabetes & $51(23.7)$ & $14(31.8)$ & $\mathrm{ns}$ \\
Hypertension & $112(52.1)$ & $39(88.6)$ & $<0.001$ \\
OSAS & $125(58.1)$ & $29(65.9)$ & $\mathrm{ns}$ \\
NAFLD & $173(80.5)$ & $42(95.5)$ & 0.016 \\
Osteoarthritis & $149(69.3)$ & $42(95.5)$ & $<0.001$ \\
CVD & $75(34.9)$ & $34(77.3)$ & $<0.001$ \\
CKD & $5(2.3)$ & $6(13.6)$ & 0.001 \\
Psychiatric disease & $43(20.0)$ & $6(13.6)$ & $\mathrm{ns}$ \\
BED & $14(6.5)$ & $0(0)$ & $\mathrm{ns}$ \\
\hline
\end{tabular}

Data are presented as $n(\%)$ or mean \pm SD. BMI, body mass index; OSAS, sleep apnea syndrome; NAFLD, non-alcoholic fatty liver disease; CVD, cardiovascular disease; CKD, chronic kidney disease; BED, binge eating disorder.

Statistical Analysis

Data are shown as means \pm standard deviations for quantitative measures, and frequency percentage for categorical variables. Baseline clinical characteristics were compared in older and younger patients with the unpaired Student's $t$ test for categorical variables and $\chi^{2}$ test for categorical variables. The efficacy of the rehabilitation program was tested in each group comparing with Student's $t$ test for paired data selected quantitative parameters collected at the beginning and at the end of the program. The percentage changes in the different parameters during the program were then calculated and the difference in percent changes between the two groups were tested by unpaired Student's $t$ test. All statistical analyses were performed using the IBM SPSS Statistics 21.0 software.

\section{Results}

The study included a total of 259 adult patients, 215 aged $<65$ years (young; 70 males and 145 females, mean age $48.2 \pm 11.5$ years and mean BMI $43.9 \pm 9.4$ ) and 44 aged $>65$ years (old; 16 males and 28 females, mean age $69.3 \pm 3.5$ years and mean BMI $41.9 \pm 6.9$ ), consecutively admitted to the MRP between January 1st, 2016, and April 1st, 2017. Baseline characteristics of the two groups registered at admission are reported in Table 1. The old group presented a higher burden of comorbidities, with a significantly higher prevalence of hypertension (52.1 vs. $88.6 \%, p<0.001)$, non-alcoholic fatty liver disease $(80.5$ vs. $95.5 \%, p=$ 0.016 ), symptomatic OA ( 69.3 vs. $95.5 \%, p<0.001$ ), cardiovascular disease ( 34.9 vs. $77.36 \%$, $p<0.001$ ), and chronic kidney disease (CKD; 2.3 vs. 13.6\%, $p=0.001$ ). Physical fitness was lower in the old group, who performed worse in all functional tests. In particular, they achieved lower peak PO (PPO: $101.5 \pm 25.5$ vs. $134.3 \pm 42.3 \mathrm{~W} ; p<0.001$ ) and peak $\mathrm{VO}_{2}$ $\left(\mathrm{VO}_{2 \text { peak: }} 16.1 \pm 3.1\right.$ vs. $\left.18.3 \pm 4.5 \mathrm{ml} / \mathrm{kg} / \mathrm{min} ; p=0.012\right)$, shorter distance at 6MWT (367.5 \pm 116.1 vs. $441.7 \pm 99.4 \mathrm{~m} ; p<0.001)$, and less repetitions on CST $(11.5 \pm 2.8$ vs. $13.3 \pm 4.0$ stands; $p=0.005)$ and ACT ( $16.1 \pm 3.4$ vs. $18.7 \pm 4.6$ curls; $p=0,005)$. 
Table 2. Anthropometric, metabolic, and cardiovascular parameters registered at the beginning and at the end of the rehabilitation program (young $<65$ years old vs. old $>65$ years old)

\begin{tabular}{|c|c|c|c|c|c|c|c|c|}
\hline & \multicolumn{4}{|l|}{ Young } & \multicolumn{4}{|l|}{ Old } \\
\hline & beginning & end & delta, $\%$ & $p$ value & beginning & end & delta, \% & $p$ value \\
\hline Body weight, kg & $121.4 \pm 29.2$ & $116.0 \pm 26.8$ & $-4.3 \pm 1.8$ & $<0.001$ & $112 \pm 21.6$ & $107.6 \pm 20.3$ & $-3.8 \pm 1.7$ & $<0.001$ \\
\hline BMI & $43.9 \pm 9.4$ & $41.9 \pm 8.7$ & $-4.4 \pm 2.2$ & $<0.001$ & $41.9 \pm 6.9$ & $40.2 \pm 6.5$ & $-3.9 \pm 1.6$ & $<0.001$ \\
\hline Waist circumference, $\mathrm{cm}$ & $130.4 \pm 18.6$ & $124.9 \pm 17.6$ & $-4.1 \pm 2.2^{*}$ & $<0.001$ & $129.3 \pm 14.9$ & $124.9 \pm 14.4$ & $-3.4 \pm 2.0^{*}$ & $<0.001$ \\
\hline Neck circumference, $\mathrm{cm}$ & $43.9 \pm 5.1$ & $42.3 \pm 5.4$ & $-3.5 \pm 6.4$ & $<0.001$ & $44.0 \pm 4.2$ & $42.8 \pm 4.1$ & $-2.7 \pm 2.0$ & $<0.001$ \\
\hline Fasting blood glucose, $\mathrm{mg} / \mathrm{dL}$ & $101.3 \pm 29.7$ & $90.5 \pm 14.6$ & $-8.1 \pm 12.9$ & $<0.001$ & $104.6 \pm 23.8$ & $93.5 \pm 11.3$ & $-8.3 \pm 13.5$ & $<0.001$ \\
\hline Creatinine, mg/dL & $0.96 \pm 2.27$ & $0.99 \pm 2.2$ & $+7.0 \pm 16.0$ & $<0.001$ & $0.93 \pm 0.3$ & $1.0 \pm 0.4$ & $+8.0 \pm 16.4$ & 0.014 \\
\hline Total cholesterol, mg/dL & $182.7 \pm 34.4$ & $154.2 \pm 31.8$ & $-15.0 \pm 12.6$ & $<0.001$ & $179.3 \pm 37.4$ & $151.7 \pm 29.9$ & $-14.0 \pm 14.1$ & $<0.001$ \\
\hline LDL-cholesterol, mg/dL & $108.8 \pm 29.2$ & $89.7 \pm 27.5$ & $-16.7 \pm 18.3$ & $<0.001$ & $105.0 \pm 32.5$ & $84.4 \pm 25.9$ & $-17.5 \pm 18.0$ & $<0.001$ \\
\hline HDL-cholesterol, mg/dL & $48.2 \pm 15.2$ & $42.76 \pm 12.5$ & $-9.2 \pm 15.8$ & $<0.001$ & $50.5 \pm 17.7$ & $44.1 \pm 12.2$ & $-9.3 \pm 16.0$ & $<0.001$ \\
\hline Triglycerides, mg/dL & $129.3 \pm 62.4$ & $108.4 \pm 44.7$ & $-10.5 \pm 26.4^{*}$ & $<0.001$ & $113.9 \pm 55.7$ & $107.1 \pm 43.8$ & $-0.8 \pm 36.2^{*}$ & ns \\
\hline $\mathrm{HbA1c}, \mathrm{mmol} / \mathrm{moL}$ & $42.1 \pm 11.5$ & $39.8 \pm 9.5$ & $-4.7 \pm 4.9^{*}$ & $<0.001$ & $43.4 \pm 10.0$ & $41.9 \pm 8.2$ & $-3.0 \pm 4.1^{*}$ & $<0.001$ \\
\hline Uric acid, mmol/L & $6.5 \pm 1.5$ & $6.9 \pm 2.1$ & $+4.5 \pm 22.1$ & 0.005 & $6.8 \pm 1.7$ & $7.0 \pm 2.3$ & $+2.8 \pm 18.5$ & ns \\
\hline Systolic blood pressure, mm Hg & $130.2 \pm 19.0$ & $122.7 \pm 10.7$ & $-5.4 \pm 11.1$ & $<0.001$ & $133.2 \pm 17.2$ & $122.4 \pm 10.0$ & $-7.2 \pm 9.4$ & $<0.001$ \\
\hline Diastolic blood pressure, $\mathrm{mm} \mathrm{Hg}$ & $77.9 \pm 11.0$ & $72.9 \pm 7.7$ & $-5.0 \pm 13.0$ & $<0.001$ & $78.3 \pm 12.1$ & $73.3 \pm 6.1$ & $-7.2 \pm 9.4$ & 0.006 \\
\hline $\mathrm{FFM}, \mathrm{kg} / \mathrm{m}$ & $66.0 \pm 15.3$ & $64.3 \pm 14.4$ & $-2.4 \pm 5.0$ & $<0.001$ & $63.6 \pm 13.4$ & $62.4 \pm 13.1$ & $-1.7 \pm 3.0$ & $<0.001$ \\
\hline $\mathrm{FM}, \mathrm{kg} / \mathrm{m}$ & $55.1 \pm 19.1$ & $51.5 \pm 17.6$ & $-6.2 \pm 6.7$ & $<0.001$ & $47.7 \pm 13.2$ & $44.4 \pm 12.0$ & $-6.7 \pm 4.6$ & $<0.001$ \\
\hline $\mathrm{TBW}, \mathrm{L} / \mathrm{m}$ & $49.5 \pm 12.3$ & $47.7 \pm 11.1$ & $-3.0 \pm 5.6$ & $<0.001$ & $48.1 \pm 11.7$ & $46.4 \pm 10.4$ & $-3.0 \pm 4.2$ & $<0.001$ \\
\hline
\end{tabular}

Data are presented as mean \pm SD. BMI, body mass index; HbA1c, glycated hemoglobin; FFM, fat-free mass; FM, fat mass; TBW, total body water; ${ }^{*} p$ value $<0.05$ between the variation between the 2 groups.

Anthropometric and cardiometabolic parameters of the two groups at the beginning and at the end of the MRP are reported in Table 2 . Both groups showed a statistically significant reduction in BW (young: $-4.3 \pm 1.8 \%$, old: $-3.8 \pm 1.7 \%$; $p=0.122$ ), BMI (young: $-4.4 \pm 2.2 \%$, old: $-3.9 \pm 1.6 \% ; p=0.110$ ), WC (young: $-4.1 \pm 2.2 \%$, old: $-3.4 \pm 2.0 \% ; p<0.05$ ), and neck circumference (young: $-3.5 \pm 6.4 \%$, old: $-2.7 \pm 2.0 \%$; $p=0.115$ ). In both groups, a significant improvement was observed in both Glc (young: $-8.1 \pm 12.9 \%$, old: $-8.3 \pm 13.5 \% ; p=0.941$ ) and HbA1c levels (young: $-4.7 \pm 4.9 \%$, old: $-3.0 \pm 4.1 \% ; p<0.05$ ), TC (young: $-15.0 \pm 12.6 \%$, old: $-14.0 \pm 14.1 \% ; p=0.678$ ), and LDL (young: $-16.7 \pm 18.3 \%$, old: $-17.5 \pm 18.0 \% ; p=0.786$ ). In the YOUNG group, only blood levels of TG significantly decreased (young: $-10.5 \pm 26.4 \%$, old: $+0.8 \pm 36.2 \% ; p=0.054$ ), while levels of uric acid increased significantly in both groups (young: $+4.5 \pm 22.1 \%$, old: $+2.8 \pm 18.5 \%$; $p=0.611$ ). Moreover, both groups showed a significant decrease of HDL (young: $-9.2 \pm 15.8 \%$, old: $-9.3 \pm 16.0 \% ; p=0.954$ ), and an increase of creatinine levels (young: $+7.0 \pm 16.0 \%$, old: $+8.0 \pm 16.4 \%$; $p=0.728$ ). Finally, a statistically significant reduction was observed in both systolic (young: $-5.4 \pm 11.1 \%$, old: $-7.2 \pm 9.4 \%$; $p=0.267$ ) and diastolic blood pressure (young: $-5.0 \pm 13.0 \%$, old: $-4.42 \pm 15.4 \% ; p=0.809$ ). Data regarding body composition at the beginning and at the end of the rehabilitation program are also reported in Table 2. In both groups, a significant reduction in fat mass (young: -6.2 $\pm 6.7 \%$, old: $-6.7 \pm 4.6 \% ; p=0.585$ ), fat-free mass (young: $-2.4 \pm 5.0 \%$, old: $-1.7 \pm 3.0 \% ; p=$ 0.286 ), and TBW (young: $-3.0 \pm 5.6 \%$, old: $-3.0 \pm 4.2 \% ; p=0.993$ ) was observed.

Physical fitness parameters of the two groups at the beginning and at the end of the rehabilitation program are reported in Table 3. In the young group, a statistically significant improvement of parameters regarding both aerobic capacity $(+6.2 \pm 14.3 \%$ in absolute $\mathrm{VO}_{2 \text { peak, }}+10.8 \pm 17.0 \%$ in $\mathrm{VO}_{2 \text { peak }} / \mathrm{kg},+15.3 \pm 30.5 \%$ in $\left.6 \mathrm{MWT}\right)$ and muscle strength $(+26.9 \pm$ $25.1 \%$ in CST, $+27.3 \pm 27.3 \%$ in ACT) was observed. In the OLD group, an increase in the distance walked during 6MWT was observed $(+28.7 \pm 22.0 \%)$, with unchanged peak CPET parameters, while muscle strength increased similarly to the YOUNG group in both CST $(+24.8 \pm 30.5 \%)$ and ACT $(+15.2 \pm 19.6 \%)$. Regarding submaximal CPET parameters, a significant increase in $\mathrm{PO}$ at $\mathrm{VT}_{1}\left(\mathrm{PO}_{\mathrm{VT} 1}\right)$ was observed in both groups (young: $+13.2 \pm 21.5 \%$, 
Table 3. Variation of functional performance between admission and discharge in the two groups (young < 65 years old vs. old $>65$ years old)

\begin{tabular}{|c|c|c|c|c|c|c|c|c|}
\hline & \multicolumn{4}{|l|}{ Young } & \multicolumn{4}{|l|}{ Old } \\
\hline & beginning & end & delta, \% & $p$ value & beginning & end & delta, \% & $p$ value \\
\hline $\mathrm{VO}_{2 \text { peak }}, \mathrm{mL} / \mathrm{min}$ & $2,087 \pm 579.9$ & $2,199 \pm 610.7$ & $+6,2 \pm 14,4^{*}$ & $<0.001$ & $1,767 \pm 487.5$ & $1,755 \pm 532.5$ & $+0.3 \pm 17.8^{*}$ & ns \\
\hline $\mathrm{VO}_{2 \text { peak }}, \mathrm{mL} / \mathrm{kg} / \mathrm{min}$ & $18.3 \pm 4.5$ & $20.2 \pm 5.1$ & $+10.8 \pm 15.1^{*}$ & $<0.001$ & $16.1 \pm 3,1$ & $16.6 \pm 3.8$ & $+4.0 \pm 18.2^{*}$ & ns \\
\hline $\mathrm{PPO}, \mathrm{W}$ & $134.3 \pm 42.3$ & $146.6 \pm 47.3$ & +9.8 14.6 & $<0.001$ & $101.5 \pm 25,5$ & $106.1 \pm 32.8$ & $+4.1 \pm 19.8$ & ns \\
\hline $\mathrm{VO}_{2 \mathrm{VT} 1}, \mathrm{~mL} / \mathrm{min}$ & $1,396 \pm 391.3$ & $1,473 \pm 375.9$ & $+7.1 \pm 16.4^{*}$ & $<0.001$ & $1,310 \pm 307,3$ & $1,285 \pm 341.3$ & $-0.5 \pm 17.3^{*}$ & ns \\
\hline $\mathrm{VO}_{2 \mathrm{VT} 1}, \mathrm{~mL} / \mathrm{kg} / \mathrm{min}$ & $12.0 \pm 3.1$ & $13.3 \pm 3.4$ & $+11.8 \pm 17^{*}$ & $<0.001$ & $11.9 \pm 2.3$ & $12.1 \pm 2.5$ & $+3.0 \pm 17.4^{*}$ & ns \\
\hline $\mathrm{PO}_{\mathrm{VT} 1}, \mathrm{~W}$ & $72.5 \pm 25.9$ & $80.0 \pm 26.9$ & $+13.2 \pm 21.5$ & $<0.001$ & $60.74 \pm 14.1$ & $64.6 \pm 15.5$ & $+8.4 \pm 19.0$ & 0.034 \\
\hline 6MWT, m & $441.7 \pm 99.4$ & $495.4 \pm 101.5$ & $+15.3 \pm 30.5$ & $<0.001$ & $367.5 \pm 116.1$ & $405.9 \pm 118.2$ & $+28.7 \pm 122.0$ & 0.002 \\
\hline 30s Chair Stands, $n$ & $13.3 \pm 4.0$ & $16.6 \pm 4.2$ & $+26.9 \pm 25.1$ & $<0.001$ & $11.5 \pm 2.8$ & $13.9 \pm 2.9$ & $+24.8 \pm 30.5$ & $<0.001$ \\
\hline 30s Arm Curl, $n$ & $18.7 \pm 4.6$ & $23.3 \pm 5.2$ & $+27.3 \pm 27.3^{*}$ & $<0.001$ & $16.1 \pm 3.4$ & $18.3 \pm 4.3$ & $+15.2 \pm 19.6^{*}$ & $<0.001$ \\
\hline
\end{tabular}

$\mathrm{VO}_{2 \mathrm{VT} 1}, \mathrm{VO}_{2}$ registered at first ventilatory threshold; $\mathrm{VO}_{2 \text { peak }}, \mathrm{VO}_{2}$ registered at the maximal exertion (each $\mathrm{VO}_{2}$ value was expressed both in absolute terms [mL/ $\mathrm{min}]$ and after adjustment for body weight [ $\mathrm{mL} / \mathrm{kg} / \mathrm{min}]$ ); $\mathrm{PO}_{\mathrm{VT} 1}$, power output registered at first ventilatory threshold; $\mathrm{PPO}$, power output registered at the maximal exertion; 6MWT, Six-Minute Walk Test; 30s Chair Stands, 30 -s Chair Stands test; 30s Arm Curl, 30-s Arm Curl test. * $p$ value $<0.05$ between the variation between the 2 groups.

Table 4. The percentage difference (or percentage delta) in psychometric tests regarding quality of life and nutritional behavior between the beginning and the end of the rehabilitation program (young $<65$ years old vs. old $>65$ years old)

\begin{tabular}{|c|c|c|c|c|c|c|c|c|}
\hline & \multicolumn{4}{|l|}{ Young } & \multicolumn{4}{|l|}{ Old } \\
\hline & beginning & end & delta, $\%$ & $p$ value & beginning & end & delta, $\%$ & $p$ value \\
\hline BES score & $31.8 \pm 8.3$ & $27.5 \pm 7.8$ & $-13.5 \pm 6.02$ & $<0.001$ & $26.3 \pm 7.2$ & $25.9 \pm 6.2$ & $-4.4 \pm 15.4$ & ns \\
\hline SF36-A score & $50.7 \pm 22.2$ & $62.3 \pm 22.8$ & $+22.8 \pm 2.7$ & $<0.001$ & $46.4 \pm 21.5$ & $53.0 \pm 22.0$ & $+25.0 \pm 45.6$ & 0.027 \\
\hline SF36-B score & $53.3 \pm 20.8$ & $65.8 \pm 21.0$ & $+23.45 \pm 0.9$ & $<0.001$ & $53.1 \pm 20.2$ & $63.2 \pm 16.5$ & $+31.3 \pm 50.6$ & 0.018 \\
\hline SF36-tot score & $53.1 \pm 21.4$ & $65.2 \pm 22.1$ & $+22.7 \pm 3.2$ & $<0.001$ & $49.7 \pm 20.0$ & $58.5 \pm 19.1$ & $+27.6 \pm 44.7$ & ns \\
\hline
\end{tabular}

Data are presented as mean \pm SD. BES, Binge Eating Scale; SF36, 36-item Health Survey.

old $+8.4 \pm 19.0 \%)$, while $\mathrm{VO}_{2}$ at $\mathrm{VT}_{1}\left(\mathrm{VO}_{2 \mathrm{VT} 1}\right)$ was significantly increased only in the young, both in absolute terms (young: $+7.1 \pm 16.4 \%$, OLD: $-0.5 \pm 17.3 \% ; p<0.05$ ) and after adjustment for BW (young: $+11.8 \pm 17.0 \%$, OLD: $+3.0 \pm 17.4 \%$; $p<0.05$ ).

Regarding the perception of quality of life and alimentary behavior, the psychometric test showed that younger patients presented a statically significant improvement in all analyzed psychometric scales, while elderly patients presented only significant improvement in healthrelated quality of life (Table 4).

The comparison of the percent changes observed during the program between the two groups is also presented in Figures 1 and 2. We observed a statistically significant difference for $\mathrm{WC}, \mathrm{TG}$, and $\mathrm{HbA1}$, which showed a greater percent decrease in the young group (Fig. 1), and for $\mathrm{VO}_{2 \text { peak }}, \mathrm{VO}_{2 \mathrm{VT} 1}$ (both absolute and relative to $\mathrm{BW}$ ), and $\mathrm{ACT}$, which showed a greater percent increase in the young group (Fig. 2).

\section{Discussion}

The aim of our study was to assess the short-term effect of an intensive 3-week inpatient multidisciplinary rehabilitation program including personalized nutritional, exercise, and behavioral interventions developed for patients with severe obesity, on cardiovascular risk 


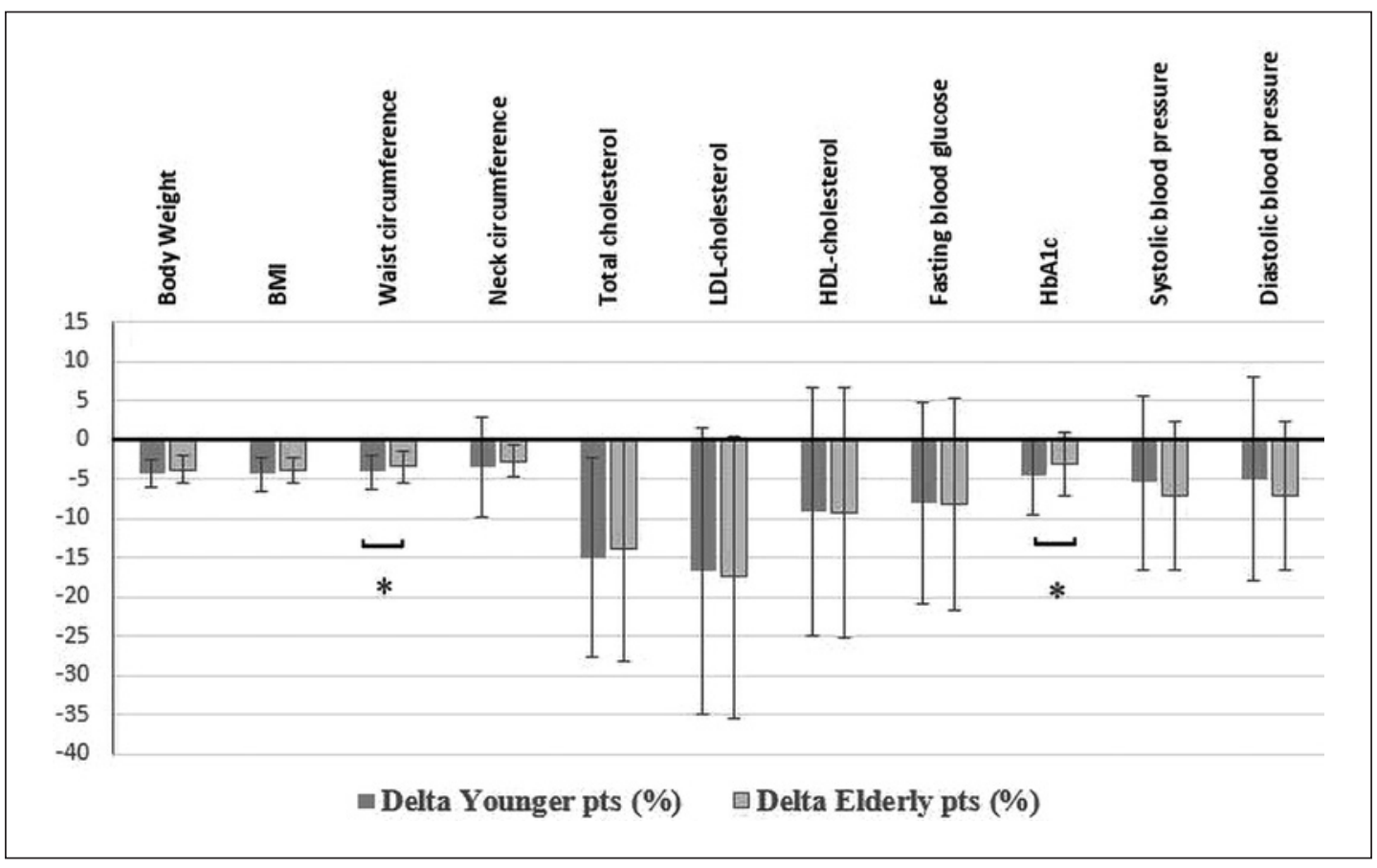

Fig. 1. Percentage differences (or delta) in anthropometric and metabolic variables from the beginning to the end of the rehabilitation program (young $<65$ years old vs. old $>65$ years old). pts, patients; BMI, body mass index. $* p<0.05$.

factors and physical performance. The results of the study show a beneficial effect of the program in younger patients, as previously demonstrated [14], but most importantly, in elderly patients with obesity. This indicates that elderly patients respond positively to intensive rehabilitation in terms of weight loss and cardiovascular health, as well as of functional performance, which is fundamental for the prevention of frailty.

Despite the shortness of our intervention, we observed a significant improvement in cardiovascular risk factors in both young and elderly patients. Levels of Glc, HbA1c, TC, LDL, as well as SBP and DBP, decreased significantly, without differences between groups. We also observed a decrease in HDL, as well as a slight increase in creatinine and uric acid levels in both groups, which have been already reported during periods of acute caloric restriction [37, 38]. The overall improvement of the cardiometabolic may translate into better control of obesity-related comorbidities and reduced need for pharmacotherapy.

Aerobic capacity at the beginning of the program was lower in the elderly group, who achieved significantly lower PPO and $\mathrm{VO}_{2 \text { peak }}$, and walked a shorter distance on 6MWT. This represents an expected result, as aerobic capacity declines with ageing [39]. At the end of the program, we observed a minor improvement of peak CPET parameters in the elderly, accompanied by a significantly greater improvement on 6MWT compared to their younger counterparts. This result could be explained by taking into consideration the type, intensity, and duration of aerobic exercise performed. Elderly patients exercised at lower intensity, especially due to comorbidities, which limited the implementation of high-intensity exercise during the program. In addition, the duration of the intervention was sufficient for enhancing submaximal performance (i.e., $\mathrm{PO}_{\mathrm{VT} 1}$, distance on $6 \mathrm{MWT}$ ), but not enough to elicit changes in PPO or $\mathrm{VO}_{2 \text { peak }}$. Finally, elderly patients were more familiar with walking and, consequently, they preferred treadmill rather than cycle ergometer as the main exercise modality during sessions, which explains their substantial improvement only on 6MWT. 


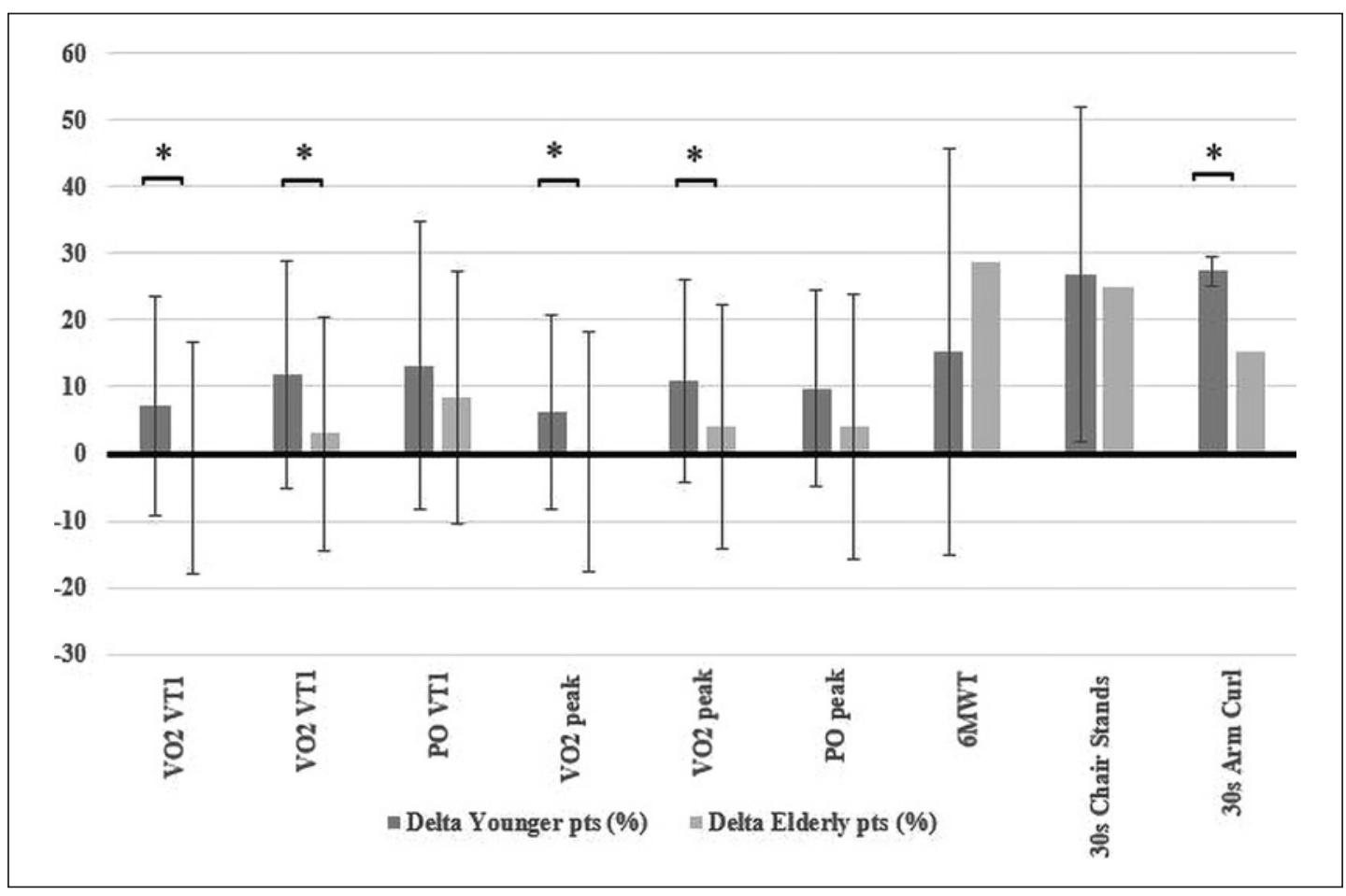

Fig. 2. Percentage differences (or delta) in physical performance variables from the beginning to the end of the rehabilitation program (younger patients $<65$ years old vs. elderly patients $>65$ years old). pts, patients; $\mathrm{VO} 2_{\mathrm{VT} 1}, \mathrm{VO}_{2}$ registered at first ventilatory threshold; $\mathrm{VO}_{2 \text { peak, }} \mathrm{VO}_{2}$ registered at the maximal exertion (each $\mathrm{VO}_{2}$ value was expressed both in absolute terms $[\mathrm{mL} / \mathrm{min}]$ and after adjustment for body weight $[\mathrm{mL} / \mathrm{kg} /$ $\min$ ]); $\mathrm{PO}_{\mathrm{VT} 1}$, power output registered at first ventilatory threshold; $\mathrm{PO}_{\text {peak, }}$, power output registered at the maximal exertion; 6MWT, Six-Minute Walking Test; 30s Chair Stands, 30-s Chair Stands test; 30s Arm Curl, 30-s Arm Curl test. * $p<0.05$.

Regarding muscle strength of upper and lower extremities, at the beginning of the program elderly patients performed fewer repetitions in both ACT and CST. Both groups improved similarly their performance in CST, while elderly improved less in ACT. This result could be explained by the fact that during strength sessions of the elderly, more emphasis was given on lower limbs. The reason for this is because loss of muscle mass and function associated with ageing process begins from the lower limbs [40], with a consequent increase in falls in this population. Our results indicate that the implementation of muscular resistance exercise in patients with obesity may contrast muscle dysfunction, which is observed especially in the elderly. In the long-term, preserving muscle function in the elderly may prevent frailty and falls, as well as the consequences related to falls.

As the prevalence of obesity increases in all age groups, obesity in the elderly becomes an important public health problem that challenges and involves several health-care professionals and delivery systems. Our multidisciplinary rehabilitation program improved significantly the cardiometabolic profile and physical fitness in elderly patients with obesity, besides their higher prevalence of chronic diseases, which was in line with that observed in the general Italian elderly population [41].

Few studies investigated the effects of a lifestyle modification program as a therapeutic approach in elderly patients with obesity. Villareal et al. [42], using a 1-year randomized controlled trial, assessed the independent and combined effects of weight loss and exercise in obese adults over 65 years old. After 52 weeks, the study demonstrated that weight loss 
Budui et al.: Inpatient Rehabilitation in Elderly Patients with Obesity

due to diet recommendations and exercise improved physical function and ameliorated frailty more than either weight loss or exercise alone, although each of those was beneficial. In a subsequent paper, Villareal and colleagues [43] showed that 18 months after the end of the previous trial, older subjects with obesity maintained the beneficial results, such as weight loss and improvement of metabolic and cardiovascular risk factors. Miller et al. [44] evaluated physical function and body composition in older adults with obesity and symptomatic knee $\mathrm{OA}$ after an intensive weight loss program including a daily caloric restriction of 1,000 kcal combined with physical exercise 3 days per week. After 6 months, the study showed a significant improvement of physical function and reduced symptoms. Furthermore, in a systematic review on the tolerance and effectiveness of physical exercise and weight loss for hip and knee osteoarthritis in elderly patients, Le Quintrec et al. [45] reported that land-based and/ or aquatic exercise resulted in reduced pain and improved function in terms of walking speed and/or distance, a result which was more substantial with combined diet and exercise interventions. The importance of exercise as part of any weight loss program in the elderly was highlighted by Villareal et al. [46]. The authors concluded that the implementation of both aerobic and resistance exercise can be effective in improving functional status and prevent the age-related decline in bone and muscle mass, thus decreasing the risk of frailty. Considering all the above, although evidence-based data to guide the treatment of obesity in the elderly are limited, it seems to make little clinical sense to promote weight loss without the inclusion of physical activity $[47,48]$.

In conclusion, our study demonstrates the beneficial clinical and functional outcomes of a 3-week multidimensional therapeutic program including diet, exercise, and behavioral therapy in elderly patients with severe obesity. Our results, especially those regarding physical fitness, support the hypothesis that obesity-related frailty may be reversible. Considering the complex clinical status and comorbidities of older patients, which may limit bariatric surgery, a residential multidisciplinary context represents an optimal setting for the initial management of obesity in the elderly.

\section{Statement of Ethics}

The study was entirely funded by the Casa di Cura "Solatrix", Rovereto (TN), Italy. All procedures performed were in accordance with the ethical standards of the institutional research committee and with the 1964 Helsinki declaration and its later amendments or comparable ethical standards. Informed consent was obtained from all individual participants included in the study.

\section{Disclosure Statement}

The authors declare no conflict of interest.

\section{References}

1 Keating C, Backholer K, Peeters A. Prevalence of overweight and obesity in children and adults. Lancet. 2014 Dec;384(9960):2107-8.

2 Field AE, Coakley EH, Must A, Spadano JL, Laird N. Dietz WH, et al. Impact of overweight on the risk of developing common chronic diseases during a 10-year period. Arch Intern Med. 2001;161(13):1581-6.

3 Alley DE, Chang VW. The changing relationship of obesity and disability, 1988-2004. JAMA. 2007 Nov;298(17): 2020-7.

4 Kyrou I, Osei-Assibey G, Williams N, Thomas R, Halder L, Taheri S, et al. Self-reported disability in adults with severe obesity. J Obes. 2011;2011:918402.

5 Eurostat. Population Projection. 2008-2060. http://ec.europa.eu/eurostat/statistics-explained/index. php?title=Archive:Population_projections\&oldid=59201 
Budui et al.: Inpatient Rehabilitation in Elderly Patients with Obesity

6 Han TS, Tajar A, Lean ME. Obesity and weight management in the elderly. Br Med Bull. 2011;97(1):169-96.

7 Gustafson D, Rothenberg E, Blennow K, Steen B, Skoog I. An 18-year follow-up of overweight and risk of Alzheimer disease. Arch Intern Med. 2003 Jul;163(13):1524-8.

8 Hubbard RE, Lang IA, Llewellyn DJ, Rockwood K. Frailty, body mass index, and abdominal obesity in older people. J Gerontol A Biol Sci Med Sci. 2010 Apr;65(4):377-81.

9 Valdes AM, Andrew T, Gardner JP, Kimura M, Oelsner E, Cherkas LF, et al. Obesity, cigarette smoking, and telomere length in women. Lancet. 2005 Aug;366(9486):662-4.

10 Zamboni M, Mazzali G, Fantin F, Rossi A, Di Francesco V. Sarcopenic obesity: a new category of obesity in the elderly. Nutr Metab Cardiovasc Dis. 2008 Jun;18(5):388-95.

11 Jensen MD, Ryan DH, Donato KA, Apovian CM, Ard JD, Comuzzie AG, et al.; American College of Cardiology/ American Heart Association Task Force on Practice Guidelines, Obesity Expert Panel, 2013. Executive summary: Guidelines (2013) for the management of overweight and obesity in adults: a report of the American College of Cardiology/American Heart Association Task Force on Practice Guidelines and the Obesity Society published by the Obesity Society and American College of Cardiology/American Heart Association Task Force on Practice Guidelines. Based on a systematic review from the The Obesity Expert Panel, 2013. Obesity (Silver Spring). 2014 Jul;22(S2 Suppl 2):S5-39.

12 Yumuk V, Tsigos C, Fried M, Schindler K, Busetto L, Micic D, et al.; Obesity Management Task Force of the European Association for the Study of Obesity. European Guidelines for Obesity Management in Adults. Obes Facts. 2015;8(6):402-24.

13 Han TS, Wu FC, Lean ME. Obesity and weight management in the elderly: a focus on men. Best Pract Res Clin Endocrinol Metab. 2013 Aug;27(4):509-25.

14 Giordano F, Berteotti M, Budui S, Calgaro N, Franceschini L, Gilli F, et al. Multidimensional improvements induced by an intensive obesity inpatients rehabilitation programme. Eat Weight Disord. 2017 Jun;22(2): 329-38.

15 Donini LM, Cuzzolaro M, Spera G, Badiali M, Basso N, Bollea MR, et al. [Obesity and Eating Disorders. Indications for the different levels of care. An Italian Expert Consensus Document]. Eat Weight Disord. 2010 Mar-Jun; 15(1-2 Suppl):1-31.

16 American Diabetes Association. (2) Classification and diagnosis of diabetes. Diabetes Care. 2015 Jan;38 Suppl:S8-16.

17 Carey RM. The 1984 Report of the Joint National Committee on Detection, Evaluation, and Treatment of High Blood Pressure. Arch Intern Med. 1984 May;144(5):1045-57.

18 European Association for the Study of the Liver (EASL); European Association for the Study of Diabetes (EASD); European Association for the Study of Obesity (EASO). EASL-EASD-EASO Clinical Practice Guidelines for the Management of Non-Alcoholic Fatty Liver Disease. Obes Facts. 2016;9(2):65-90.

19 Harris JA, Benedict FG. A biometric study of human basal metabolism. Proc Natl Acad Sci USA. 1918 Dec;4(12): $370-3$.

20 Lean ME, Han TS, Deurenberg P. Predicting body composition by densitometry from simple anthropometric measurements. Am J Clin Nutr. 1996 Jan;63(1):4-14.

21 Davies RJ, Stradling JR. The relationship between neck circumference, radiographic pharyngeal anatomy, and the obstructive sleep apnoea syndrome. Eur Respir J. 1990 May;3(5):509-14.

22 Pasanisi F, Santarpia L, Finelli C. Diet Recommendations. In: Sbraccia P, Nisoli E, Vettor R, editors. Clinical management of overweight and obesity. Recommendations of the Italian Society of Obesity (SIO). Cham: Springer Nature Switzerland; 2016. p. 13-21. https://doi.org/10.1007/978-3-319-24532-4_2

23 Rotella C, Cresci B, Pala L, Dicembrini I. Therapeutic Education. In: Sbraccia P, Nisoli E, Vettor R, editors. Clinical management of overweight and obesity. Recommendations of the Italian Society of Obesity (SIO). Cham: Springer Nature Switzerland; 2016. p. 37-42. https://doi.org/10.1007/978-3-319-24532-4_4

24 Nardone G, Watzlawick P. Brief Strategic Therapy. Lanham: Rowman \& Littlefield Publishers; 2005.

25 Dalle Grave R, Centis E, Marzocchi R, El Ghoch M, Marchesini G. Major factors for facilitating change in behavioral strategies to reduce obesity. Psychol Res Behav Manag. 2013 Oct;6:101-10.

26 Fairburn CG. Overcoming Binge Eating. 2nd ed. New York: Guilford Press; 2013.

27 Beck JS. The Beck diet solution. Train your brain to think as a thin person. Birmingham: Oxmoor House; 2007.

28 Kristeller JL, Wolever RQ. Mindfulness-based eating awareness training for treating binge eating disorder: the conceptual foundation. Eat Disord. 2011 Jan-Feb;19(1):49-61.

29 Bandura A. Self-efficacy: toward a unifying theory of behavioral change. Psychol Rev. 1977 Mar;84(2):191215.

30 Ware JE, Kosinski MA, Kelle SD. SF-36 physical and mental health summary scales: a user's manual. Boston: The Health Institute: New England Medical Center; 1984.

31 Gormally J, Black S, Daston S, Rardin D. The assessment of binge eating severity among obese persons. Addict Behav. 1982;7(1):47-55.

32 Wasserman K, Whipp BJ, Koyl SN, Beaver WL. Anaerobic threshold and respiratory gas exchange during exercise. J Appl Physiol. 1973 Aug;35(2):236-43.

33 Meyer T, Lucía A, Earnest CP, Kindermann W. A conceptual framework for performance diagnosis and training prescription from submaximal gas exchange parameters-theory and application. Int J Sports Med. 2005 Feb; 26 Suppl 1:S38-48. 
ATS Committee on Proficiency Standards for Clinical Pulmonary Function Laboratories. ATS statement: guidelines for the six-minute walk test. Am J Respir Crit Care Med. 2002 Jul;166(1):111-7.

Jones CJ, Rikli RE, Beam WC. A 30-s chair-stand test as a measure of lower body strength in communityresiding older adults. Res Q Exerc Sport. 1999 Jun;70(2):113-9.

36 Rikli RE, Jones CJ. Development and Validation of a Functional Fitness Test for Community-Residing Older Adults. J Aging Phys Act. 1999;7(2):129-61.

37 Fogelholm M. Physical activity, fitness and fatness: relations to mortality, morbidity and disease risk factors. A systematic review. Obes Rev. 2010 Mar;11(3):202-21.

38 Busetto L, Sergi G, Enzi G, Segato G, De Marchi F, Foletto M, et al. Short-term effects of weight loss on the cardiovascular risk factors in morbidly obese patients. Obes Res. 2004 Aug;12(8):1256-63.

39 Bouchard DR, Soucy L, Senechal M, Dionne IJ, Brochu M. Impact of resistance training with or without caloric restriction on physical capacity in obese older women. Menopause. 2009;16(1):66-72.

40 Rejeski WJ, Marsh AP, Chmelo E, Rejeski JJ. Obesity, intentional weight loss and physical disability in older adults. Obes Rev. 2010 Sep;11(9):671-85.

41 ISTAT report 2015 https://www.istat.it/it/files/2017/09/Condizioni_Salute_anziani_anno_2015.pdf

42 Villareal DT, Chode S, Parimi N, Sinacore DR, Hilton T, Armamento-Villareal R, et al. Weight loss, exercise, or both and physical function in obese older adults. N Engl J Med. 2011 Mar;364(13):1218-29.

43 Waters DL, Vawter R, Qualls C, Chode S, Armamento-Villareal R, Villareal DT. Long-term maintenance of weight loss after lifestyle intervention in frail, obese older adults. J Nutr Health Aging. 2013 Jan;17(1):3-7.

44 Miller GD, Nicklas BJ, Davis C, Loeser RF, Lenchik L, Messier SP. Intensive weight loss program improves physical function in older obese adults with knee osteoarthritis. Obesity (Silver Spring). 2006 Jul;14(7):121930.

45 Quintrec JL, Verlhac B, Cadet C, Bréville P, Vetel JM, Gauvain JB, et al. Physical exercise and weight loss for hip and knee osteoarthritis in very old patients: a systematic review of the literature. Open Rheumatol J. 2014 Nov;8:89-95.

46 Villareal DT, Aguirre L, Gurney AB, Waters DL, Sinacore DR, Colombo E, et al. Aerobic or resistance exercise, or both, in dieting obese older adults. N Engl J Med. 2017 May;376(20):1943-55.

47 Betik AC, Hepple RT. Determinants of VO2 max decline with aging: an integrated perspective. Appl Physiol Nutr Metab. 2008 Feb;33(1):130-40.

48 Jensen GL, Hsiao PY. Obesity in older adults: relationship to functional limitation. Curr Opin Clin Nutr Metab Care. 2010 Jan;13(1):46-51. 